\title{
Post Earthquack Slope Stability Analysis of Rubble Mound Breakwater
}

\author{
Amin Moradi $^{1}$, Amir Mahmoudzadeh ${ }^{2}$, Yahya Rahim Safavi ${ }^{3}$ \\ ${ }^{1}$ Master of Technology in Civil Engineering Ph.D Scholar In Reserch Institute Of Shakhes Pajouh Esfahan, \\ Iran \\ ${ }^{2}$ Master of Technology in Civil Engineering Head of Department \& Chancellor In Reserch Institute Of \\ Shakhes Pajouh Esfahan ,Iran \\ ${ }^{3}$ Professor of Political geography
}

\section{ABSTRACT}

Rubble mound breakwaters are structures built mainly of quarried rock. Generally armourstone or artificial concrete armour units are used for the outer armour layer,which should protect the structure againist wave attack. Armour stones and concrete armoure unites in this outer layer are usually placed with care to obtain effective interlocking and consequently better stability .

\section{METHODOLOGY OF ANALYSES}

This part of the report issues the methodology suggested in the slope stability analyses of the breakwater. An appropriate method of slices has been selected for the slope stability analyses and the validity of the analyses is confirmed via the reasonable results of analyses.

\section{1-SELECTED CROSS SECTIONS:}

The critical sections of the breakwater were reasonably selected based on the determinative criteria such as encountered ocean wave angle, geotechnical design parameters for different breakwater regions and breakwater geometries. Plain strain assumption can rationally be taken into account for 2D numerical modeling since the longitudinal dimension of the breakwater is large enough comparing with its cross sectional dimensions.

\section{SOFTWARE AND METHOD OF ANALYSES}

In these methods, the soil mass above the slip surface is subdivided into a number of vertical slices. Some of slices methods can be useful either for circular or non-circular (irregular) slip surfaces.

The Morgenstern and Price (1965) limit equilibrium method implemented in the SLOPE software has been used in order to hand in the minimum factor of safeties. This method was selected since it takes the safety factor of slopes against the both mobilized moments and forces into account. In the limit equilibrium methods of slices, evaluating inter-slice forces is one of the controversial issues. The Morgenstern and Price (1965) method assumes that the inter-slice shear forces are related to the normal forces enforcing between the slices. The location of the normal force on the base of the slice is also implicitly or explicitly assumed. This method is an accurate procedure applicable to virtually all slopes geometries and soil profiles (Duncan and Wright 2005).

In the Morgenstern - Price limit equilibrium method, the Mohr-Coulomb model is used in order to define resistance of the soils. Soils geotechnical parameters including cohesion, internal friction angle, and total unit weights are implemented in the Mohr-Coulomb model.

The SLOPE software has a capability to take into account dry unit weight for the part of a soil layer settling down above the water table. The mechanical pressure of water located at see and lee sides has been defined supposing water as a no strength soil layer with the unit weight of 9.81 $\mathrm{kN} / \mathrm{m} 3$. The SLOPE built - in "Bedrock model" has been used for impenetrable bedrock layer which is referred to as the soil layer lied beneath the two formerly mentioned seabed soil layers. The slip surfaces can not penetrate and cross through this type of layer.

\section{INPUT PARAMETERS}

The geometrical and geotechnical parameters of the breakwater as well as seabed soil layers to be used in the analyses are reported herein. In addition, a brief description concerning the utilized method of slope stability analyses is presented. The required information regarding sea water levels, earthquake motion levels, and postearthquake resistance of the seabed soil layer have been extracted from the preliminary investigations performed. 


\section{3-1-SELECTED CROSS SECTIONS:}

The critical sections of the breakwater were reasonably selected based on the determinative criteria such as encountered ocean wave angle, geotechnical design parameters for different breakwater regions and breakwater geometries. Plain strain assumption can rationally be taken into account for 2D numerical modeling since the longitudinal dimension of the breakwater is large enough comparing with its cross sectional dimensions. The eight cross sections chosen for static and pseudo-static slope stability analyses are illustrated in Figure $3 \& 4$.

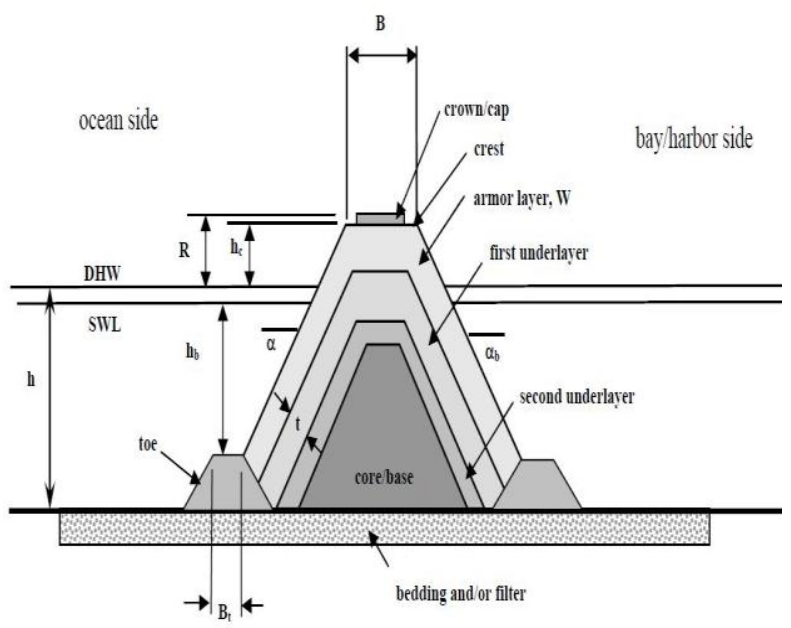

Figure 3-Seabed and Breakwater Geotechnical Parameters

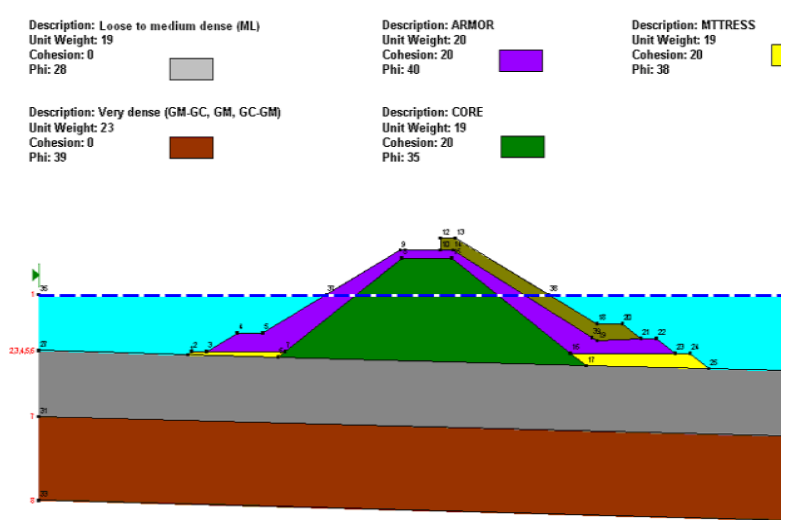

Figure 4. Section A prepared for the slope stability analyses (SLOPE software)

\section{3-3-SEISMIC COEFFICIENTS :}

The earthquake induced horizontal and vertical seismic coefficients must be determined in order to simulate the effects of forces developed by earthquake motion in the pseudo static slope stability analyses. These seismic forces are equal to any given slice weight multiplied by the seismic coefficients and applied to the mass center of the slice.
Most of the practical codes recommend that the horizontal seismic coefficient can be defined as the function of peak horizontal acceleration (PHA). According to PIANC and EC8 guidelines, seismic horizontal coefficient can be obtained as follows:

$k_{h}=0.5 \times \frac{a_{\text {max }}}{g}$

Where:

amax $=$ Peak Horizontal Acceleration at the ground surface. The values of amax for both earthquake levels were presented in the tender documents.

$\mathrm{g}=$ gravity acceleration

The horizontal seismic coefficient implemented in the earthquakes are referred to as the seismic motions with 75 and 475 years return period, respectively.

\section{3-4-WATER LEVELS:}

Since the breakwater is comprised of high permeability rockfill materials the seepage analysis is not required and the water tables at the lee and see sides have similar elevations with respect to the data sheet.

- MHHW = Mean Higher High Water

- MLHW = Mean Lower High Water

- MSL = Mean Sea Level

- MHLW = Mean Higher Low Water

- MLLW = Mean Lower Low Water

For a given cross section of the breakwater, both see and lee side slopes are modeled for slope stability analysis. Besides, two types of potentially slip surfaces including circular and block shaped are examined to best find the critical slip surface in each slope. The circular slip surfaces have been specified using a couple of grids and radiuses. Using a trial procedure, the positions and the inclinations of grids and radiuses have appropriately been determined in a manner that the most critical slip surfaces to be covered. Similarly, the block specified slip surfaces have been assigned in the positions having most slipping potential.

\section{GEOTECHNICAL INVESTIGATION}

A geotechnical investigation of the sea bed is required to determine the type of founding material and its extent. The results of this investigation will have a direct bearing on the type of cross-section of the breakwater.

- $\quad$ soft or hard rock (like coral reefs or granite);

- $\quad$ sand (as found on beaches);

- clay (as in some mangrove areas);

- soft to very soft clay, silt or mud (as found along some river banks, mangroves andother tidal areas). 


\section{WAVE HINDCASTING}

The height of wave incident on a breakwater generally determines the size and behavior of the breakwater. It is hence of the utmost importance to obtain realistic values of the waves expected in a particular area. Behaviour of water waves is one of the most intriguing of nature's phenomena. Waves manifest themselves by curved undulations of the surface of the water occurring at periodic intervals. They are generated by the action of wind moving over a waterbody; the stronger the wind blows, the higher the waves generated. They may vary in size from ripples on a pond to large ocean waves as high as 10 metres.

Wind generated waves cause the most damage to coastal structures and if winds of a local storm blow towards the shore, the storm waves will reach the shore or beach in nearly the form in which they were generated. However, if waves are generated by a distant storm, they travel hundreds of miles of calm sea before reaching the shore as swell. As waves travel across the sea they decay (they loose energy and get smaller and smaller) and only the relatively larger waves reach the shore in the form of swell.

\section{Material needs assessment:}

Given that most breakwaters consist of either rock or concrete or a mixture of both,

\section{CROSS-SECTIONAL DESIGN}

a suitable cross-sectional design for the breakwater has to be produced taking into consideration all the previous data, first is :

- $\quad$ water depths (in deep water, solid vertical sides are preferred to save on material);

- type of foundation (if ground is soft and likely to settle, then a rubble breakwater is recommended);

- height of waves (rubble breakwaters are more suitable than solid ones in the presence of larger waves);

- availability of materials (if no rock quarries are available in the vicinity of the project, then rubble breakwaters cannot be economically justified).

- For rubble mound or rock breakwaters:

- If a thin layer of loose or soft material exists above a hard layer, then this should be removed to expose the hard interface and the breakwater built on this surface.

- The material grading should be in the range of 1 to 500 kilograms for the fine core, 500 to 1000 kilograms for the underlayer and 1000 to 3000 kilograms for the main armour layer, Figure 5.

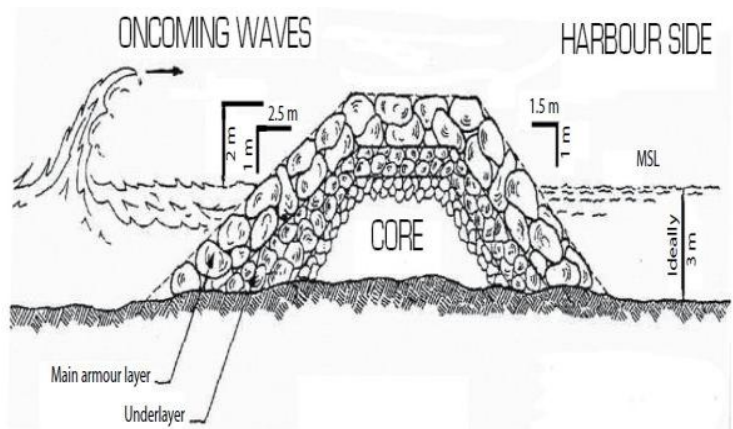

Figure 5 ,Rubble mound breakwater on hard ground

- In general, rock breakwaters absorb most of the wave energy that falls on them and reflect very little disturbance back from the sloping surface.

- Dust and fine particles should not be placed in the core as these will wash away and cause the breakwater top to settle unevenly.

\section{DESIGN METHOD FOR ROCK SLOPES}

The design of a breakwater or rock slope is often concentrated around extreme conditions close to or exceeding the estimated design life of the structure. But that is only a part of the whole picture. The full extreme distribution of wave conditions: wave heights, wave periods and water levels, should be considered.

The design of a composite or rubble mound breakwater in a tsunami zone is thus a complex process. Not only does the stability of the armour have to be checked against wind waves in the area, but the stability of the armour against tsunami should also be checked. Importantly, the landside part of the structure should also be checked for potential scour due to the wave as it starts to overtop. It should be noted that it is likely that most of the landside toe failure occurs during the initial overtopping, as once a large inundation height is established behind the breakwater the current would probably flow at a higher level, and thus scour would be less significant. Finally, the effect of the returning wave should also be checked, as this can result in the inverse process and lead to the destruction of many structures that survived the initial wave attack, as was evident in the Tohoku area.( STABILITY OF RUBBLE MOUND BREAKWATERS AGAINST SOLITARY WAVES Miguel Esteban1, Izumi Morikubo2, Tomoya Shibayama3, Rafael Aranguiz Muñoz4, Takahito Mikami5, Nguyen Danh Thao6, Koichiro Ohira7 and Akira Ohtani8) 


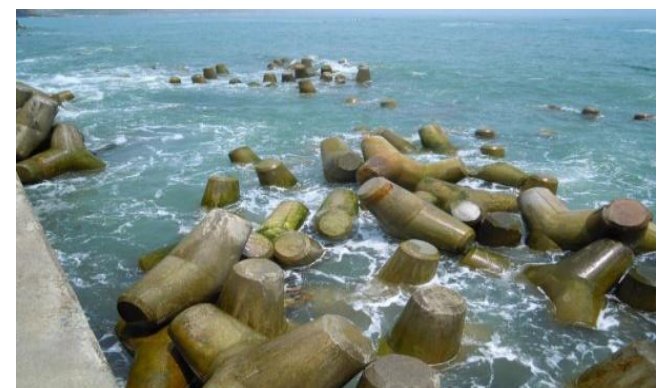

Figure 6-A , tetrapod for break water

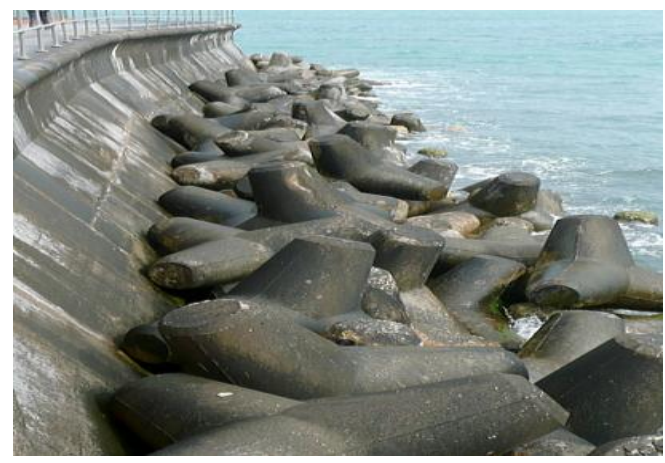

Figure 6-B , tetrapod for break water

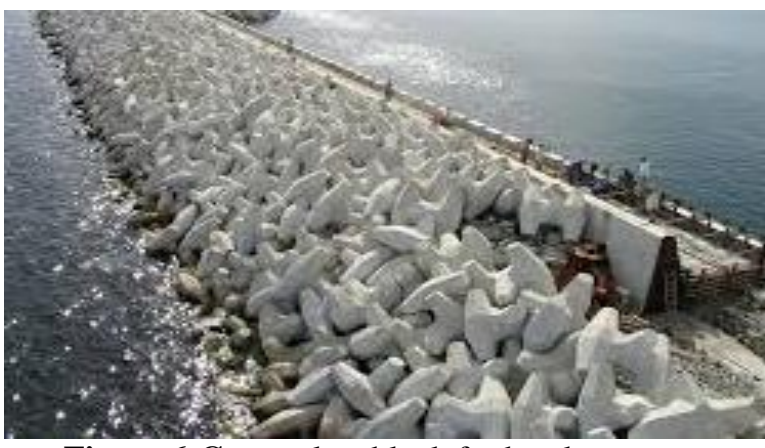

Figure 6-C , sample xblock for break water

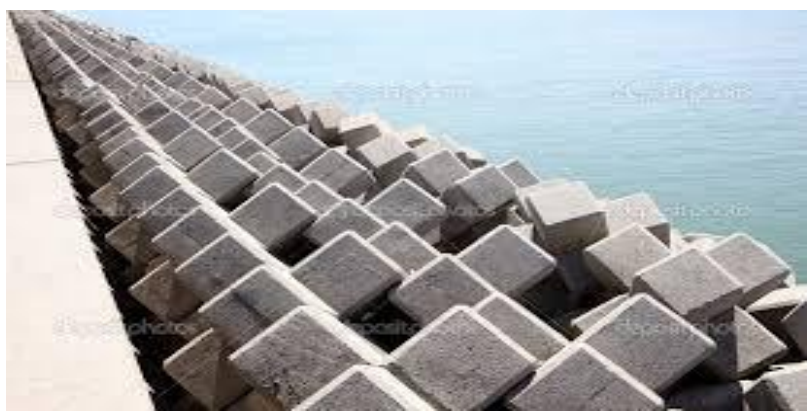

Figure 6-D ,sample accropode for break water

\section{POST-EARTHQUAKE STABILITY ANALYSES}

It is assumed that the design earthquake occurs during the lifetime of the breakwater and seismic pore water pressure develops and rises up in the liquefiable layer due to the ground strikes. The shear resistance of such soil varies from its preearthquake static resistance since the soil particles are enforced to be rearranged due to the seismic pore water pressure development. This shear resistance is known as post-earthquake shear resistance and one can evaluate the post-earthquake resistance using a reasonable approach proposed by the researchers (Seed and Harder 1990).

This shear resistance has been implemented in the SLOP software as a function correlating post-earthquake shear resistance to effective overburden pressure within the soil layer.

Pore-Water Pressure vs. Slice \#

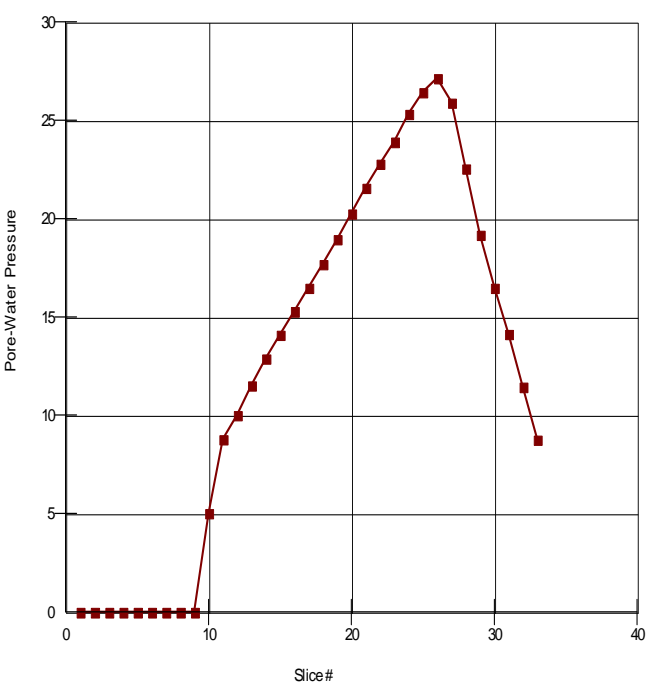

Figure 7.Variations of pore water pressure at the slip surface

Shear Resistance vs. Slice \#

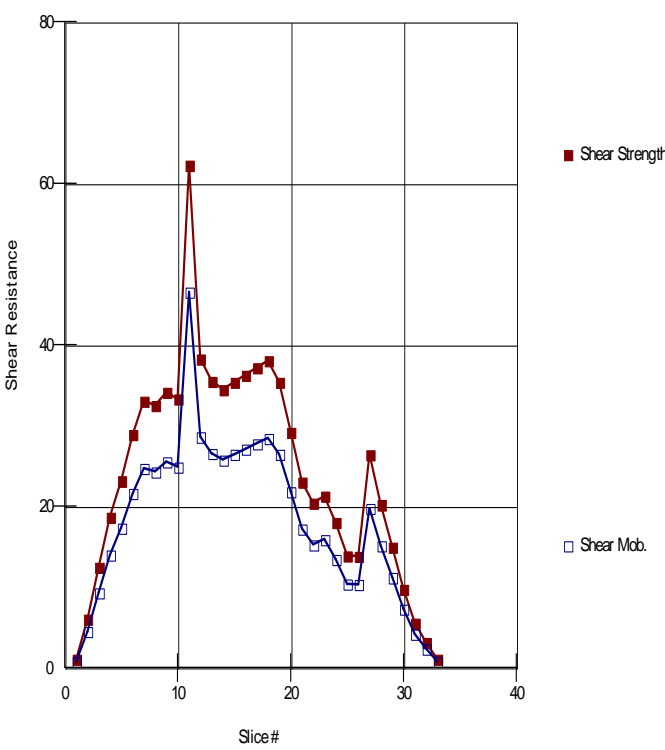

Figure 8. Variations of shear strength and mobilized shear stress at the slip surface 


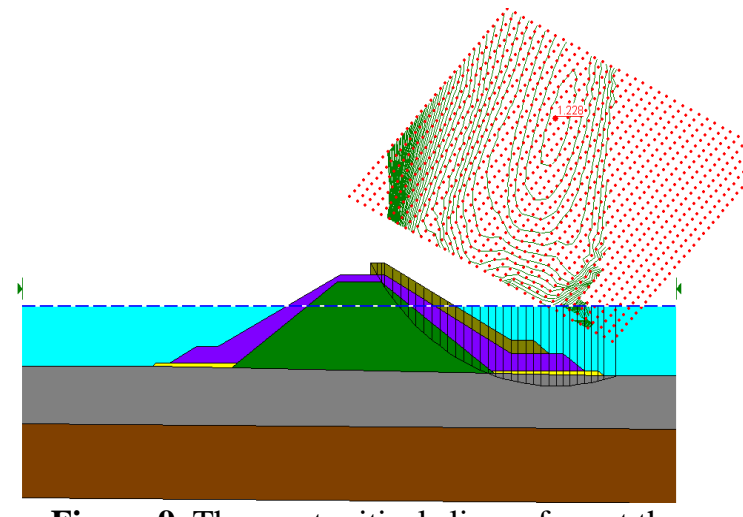

Figure 9. The most critical slip surface at the section $\mathrm{A} 1$, at see side slope having type material under level 1 seismic motion

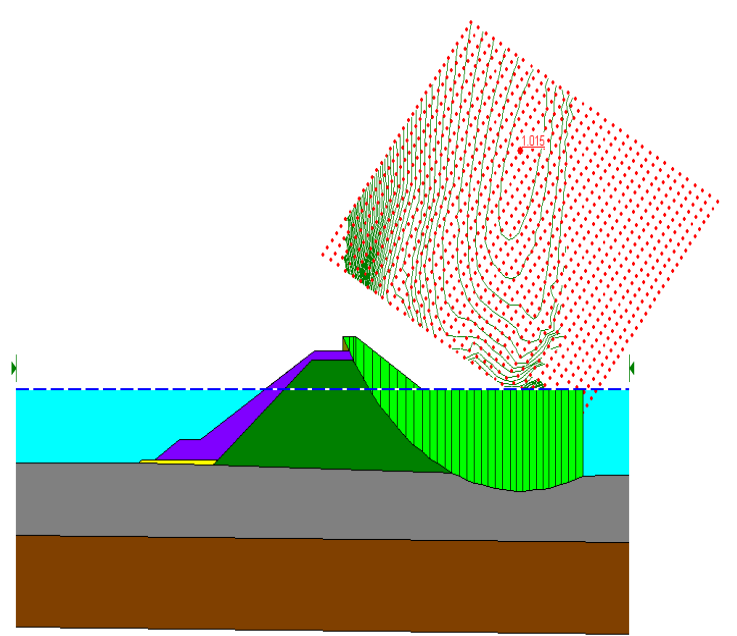

Figure 10. The most critical slip surface at the section $\mathrm{A} 1$, at see side slope having type material under level 2 seismic motion

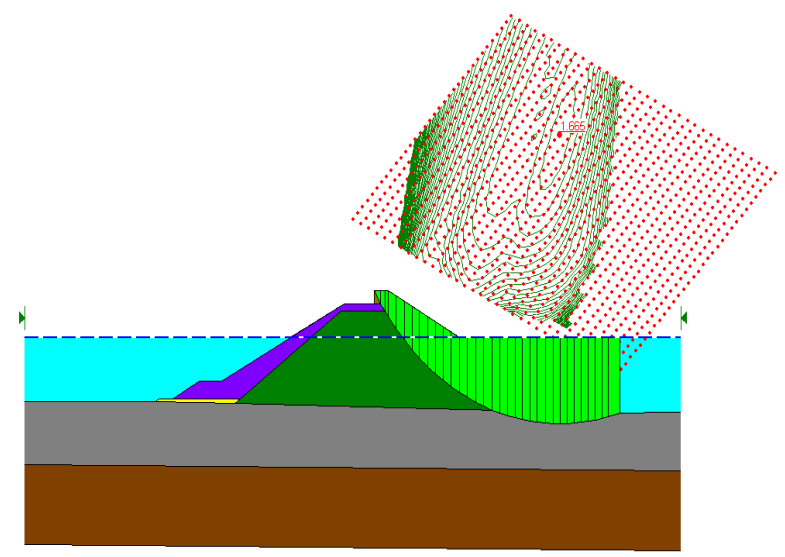

Figure 11. The most critical slip surface at the section A1, at see side slope having type material under static condition

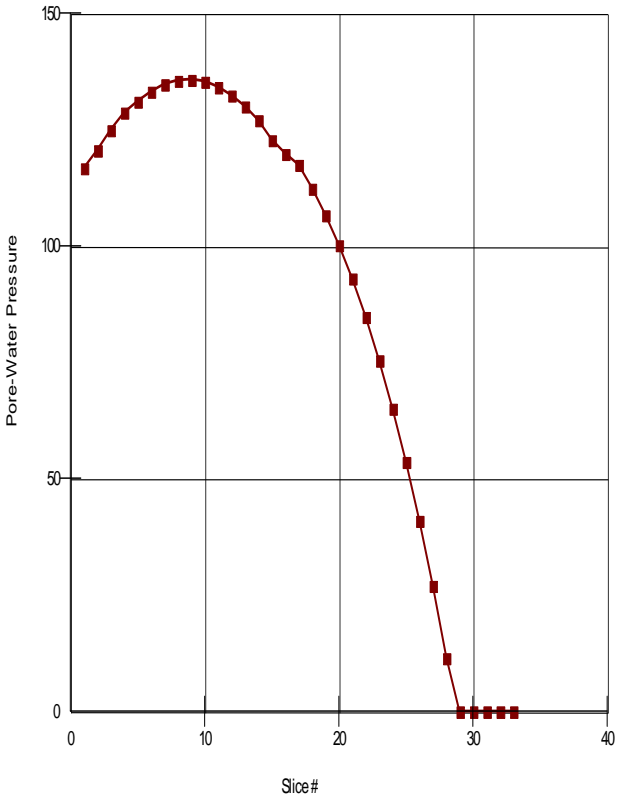

Figure 12. Variations of pore water pressure at the slip surface

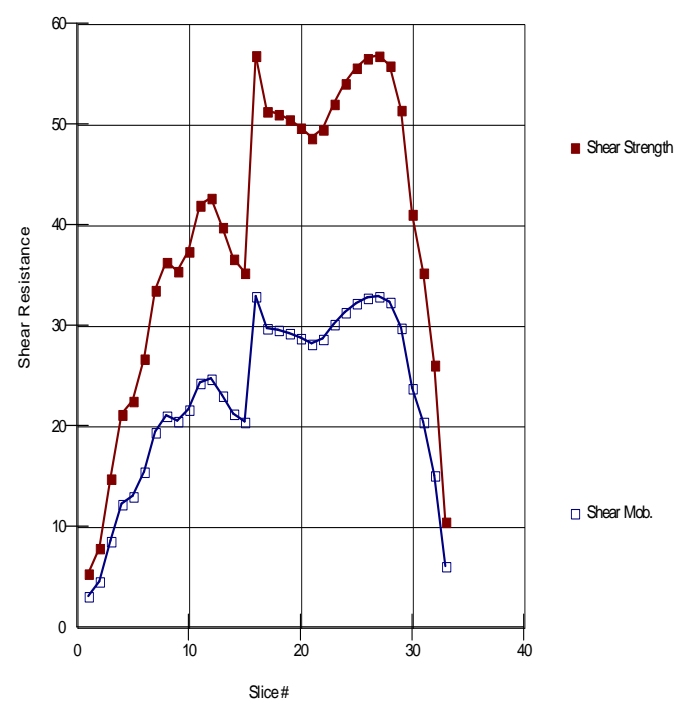

Figure 13. Variations of shear strength and mobilized shear stress at the slip surface

\section{REFERENCES}

[1] Design weight of armour stone considering the effect of extreme waves Berguzar Oztunali Ozbahceci, Aysen Ergin

[2] Geotechnical control office(1988).Guide to Rock and soil description

[3] Geotechnical Engineering Office (2007a). Engineering Geological Practice in Hong Kong (GEO Publication No. 1/2007). Geotechnical Engineering Office, Hong Kong, 278 p.

[4] Behaviour of geotextile filters in armoured slopes subjected to the action of waves Ennio M. Palmeira, , Janaina Tatto 
[5] Works Bureau (1999). Geotechnical Manual for Slopes - Guidance on Interpretation and Updating (Works Bureau Technical Circular No. 13/99). Works Bureau, Government of the Hong Kong Special Administrative Region, $12 \mathrm{p}$.

[6] Design and Construction of Berm Breakwaters By (author): Jentsje van der Meer (Van der Meer Consulting BV, The Netherlands \& UNESCO-IHE,)

[7] A probabilistic model of rubble mound armor stability Hsiang Wang. Author links open the author workspace.Steven J Peene

[8] Numerical modelling of armour block sea breakwater with smoothed particle hydrodynamics C. Altomare, A.J.C. Crespo, B.D. Rogers, J.M. Dominguez, X. Gironella , M. Gómez-Gesteira,

[9] Partial safety factor system for Tetrapod armor layer depending on shape parameter of extreme wave height distribution SeungWoo Kima, Kyung-Duck Suh

[10] Overtopping performance of different armour units for rubble mound breakwaters T. Bruce, J.W. van der Meer, L. Franco, J.M. Pearson

[11] Double layer armor breakwater stability (case study: El Dikheila Port, Alexandria, Egypt) Abdelazim M. Ali, Al Sayed I. Diwedar, 